\title{
Demographic and Socio-Eeconomic Characteristics of Patients with Congestive Heart failure Presenting to the Cardiac Emergency of Bangabandhu Sheikh Mujib Medical University
}

\author{
MD. ZAINAL ABEDIN ${ }^{1}$, SAJAL KRISHAN BANERJEE ${ }^{1}$, HARISUL HOQUE ${ }^{1}$, MONZOOR MAHMOOD ${ }^{1}$, \\ DIPAL KRISHNA ${ }^{1}$, ADHIKARY ${ }^{1}$, SHEIKH MOHAMMAD SAMSUZZAMAN ${ }^{1}$, MD. AL-AMIN ${ }^{1}$, \\ MD. RAKIBUL HASAN RASHED ${ }^{1}$, KHURSHED AHMED ${ }^{1}$, MD. AMIR HOSSAIN ${ }^{2}$ \\ ${ }^{1}$ Department of Cardiology, Bangabandhu Sheikh Mujib Medical University, Dhaka. ${ }^{2}$ Department of Cardiology, \\ Bangladesh Medical College, Dhaka
}

Address of Correspondence: Dr. Md. Zainal Abedin, Department of Cardiology, Bangabandhu Sheikh Mujib Medical University, Shahbag, Dhaka, email: zabedin96@yahoo.com.

\begin{abstract}
:
Background: Repeated hospital readmissions are frequent and increasing over time in patients with heart failure (HF). The readmission rate within 3-6 months after discharge in these patients is 10-50\%.

Aim and Objective: This study was conducted to find out the demographic and socioeconomic factors contributing to readmission of patients with congestive heart failure admitted in university cardiac center of Bangabandhu Sheikh Mujib Medical University, Shahbag, Dhaka, Bangladesh during last quarter of 2016 and early quarter of 2017.
\end{abstract}

Material and method: This was observational descriptive cross sectional study and enrolled 102 patients were enrolled for the study. Complete medical records were reviewed carefully. Results: A total of 68 men and 34 women with a mean $( \pm S D)$ age of $55( \pm 14)$ years constitute the study population. Most of the population (42\%) who belongs to age group 51-60 years had readmissions $(p<0.0004)$. De-motivation due to negative comments from surrounding causing fully or partially drugs discontinuation $(P<0.008)$ and poor adherence to drug $(P<0.004)$ were associated with readmissions.

Conclusion: After proper addressing of possible all medical factors and co morbidities, optimizing education strategies in a manner to respect the patients' level of understanding; emphasizing the importance of medication adherence, diet and life style modification, increasing the self-monitoring skills as well as supporting the spouse and family members are considered as effective measures to reduce readmission rate due to congestive heart failure.

Keywords: Congestive heart failure, Socio- economic status(SES), Emergency department,Bangabandhu Sheikh Mujib Medical University(BSMMU).

Introduction:

At the end of twentieth century, the mortality from cardiovascular diseases allocated nearly half of the statistics of mortality in industrial and a quarter of fatalities in developing countries. Among these diseases is "congestive heart failure (CHF)" which is a very important part of cardiovascular diseases and almost all heart diseases can lead to this syndrome. ${ }^{1} \mathrm{CHF}$ is a debilitating complaint associated with a large number of readmissions. ${ }^{2}$ A large body of research has revealed that CHF-related rehospitalization within six months is around $25-30 \%$, which can increase to $40 \%$ within 1 year. ${ }^{3}$ Another study showed the readmission from CHF range from $27 \%$ to $47 \%$ within three to six months after initial discharge. ${ }^{4}$ One of the study in USA showed, annual readmission rate was $56.6 \%$, median time to readmission was 91 days, with $18.3 \%$ patients readmitted within 1 month after discharge.Unplanned hospital readmission is a devastating experience for patients and is costly for society. As CHF is one of the non communicable disease causing significant mortality, morbidity, impairment of quality of life in not only developed countries but also in developing and under developed countries. Theses readmissions are affected by medical, demographic, socio environmentalfactors and are supported by various country wise studies.

Besides medical factors, other previous studies had documented that the Socio-economic Status (SES) of CHF patients was a crucial indicator, which might influence the patient's behavioral pattern, environmental exposures, and access to healthcare services. ${ }^{5}$ There is little evidence in southEast Asian countries 
includingBangladesh about the association of SES and readmission due to $\mathrm{CHF}$. Investigations carried out in the United States have suggested that most early readmissions are due to behavioral factors that are open to influence mainly inappropriate drug treatment or failure to comply with dietary measures. ${ }^{6}$ It is assumed that the result of this first study could contribute to providing the evidences for better understanding of association of socio-economical characteristics and readmission due to CHF in Bangladeshi patients; also it is probable that it would be useful for other developing countries with similar circumstance to Bangladesh.

\section{Material and methods:}

This research is a descriptive observational study. One hundred and two women and men with congestive heart failure in university cardiac center of Bangabandhu Sheikh Mujib Medical University, Shahbag, Dhaka, Bangladesh during last quarter of 2016 and early quarter of 2017 were selected with purposive sampling method.Consecutive admissions were screened daily to identify eligible patients who have arrived in cardiac emergency room; Department of Cardiology required to have an admission diagnosis of congestive heart failureandwas enrolled in this study on the basis of inclusion and exclusion criteria with history of at least one well documented hospitalization for congestive heart failure.All essential data on the patients were recorded in a designed checklist. Data were collected through a face-to-face interview with the patients and their attendants and from patients' hospital files classified into three categories including demographic information, potential confounding variables, and information about the patients' SES.

\section{Statistical analysis:}

All the data was checked and edited after collection. Continuous variable was expressed as Mean \pm Standard Deviation. Categorical variable was presented by frequency, percentage and graph. Chi-square test was used to see the association between socio-environmental factors and readmission where $\mathrm{P}$ value of $<0.05$ was considered statistically significant. Statistical analysis was done using SPSS (Statistical package for social sciences) with version 23 software programme.

\section{Results:}

The final total 102 patients with congestive heart failure were included. Table 1: showing 68 (67\%) men and 34 (33\%) women with a mean ( \pm Standard Deviation) of subjects' age was $55( \pm 14)$ years constitute the study population. Most of the population (42\%) belong to age group 51-60 years (Age ranging from 18-80+ years) had readmissions ( $\mathrm{P}<0.0004)$ (Fig.1). Almost all of them (98\%)were married.Most of the $(55 \%)$ population came from village and upazilla area, $41 \%$ were from city areas and rest 4\% from district. Majority population (59\%) was illiterate or has primary level education (Table. 1).Half of the population $(50 \%)$ was retired and only $29 \%$ were continuing their job. About two third of population (62\%) were from middle class income group (11500-200000Tk) and there was total absence from upper income group. $62.7 \%$ were currently or former smoker (Table.2).Among 102 population, 39 (38\%) had history of single hospitalization within last year of index hospitalization. $18 \%$ population had four or more hospitalization within last year of index hospitalization. Nineteen and sixteen percent population had two and three hospitalization within last year of index hospitalization respectively. Demotivation due to negative comments from surrounding causingfully or partially drug discontinuation was present in $38.2 \%$ population $(\mathrm{P}<0.008)$.

Table 1

Socio-demographic parameters of the study patients $(n=102)$.

\begin{tabular}{llcc}
\hline $\begin{array}{l}\text { Socio-demographic } \\
\text { parameters }\end{array}$ & Distribution & $\begin{array}{r}\text { Frequency } \\
(\mathrm{n}=102)\end{array}$ & $\begin{array}{c}\text { Percentage } \\
(\%)\end{array}$ \\
\hline Age (Mean \pm SD) & Years & & $55 \pm 14$ \\
Gender & Male & 68 & 66.7 \\
& Female & 34 & 33.3 \\
Marital & Married & 100 & 98 \\
status & Single & 02 & 02 \\
Area of & Village & 31 & 30.4 \\
residence & Upazilla & 25 & 24.5 \\
& District & 4 & 3.9 \\
& City & 42 & 41.2 \\
Educational & No education & 20 & 19.6 \\
status & Primary & 32 & 31.4 \\
& High school & 28 & 27.5 \\
& Graduation & 22 & 21.6 \\
\hline
\end{tabular}

$\%=$ Percentage of frequency in each group

$\mathrm{n}=$ Number of subjects

$\mathrm{SD}=$ Standard Deviation

Significant percent (63\%) population had family caregiver. During hospitalization, 67\% population got full family help during staying at home. Large percent (73\%) of population had partial adherence to dietand $56 \%$ had no adherence to advised lifestyle. Fig. 2 showing significant number of patients $(76 \%)$ had partial or non-adherence to drugs ( $\mathrm{P}$ $<0.004)$. Huge percent $(91 \%)$ of population was not immunized against influenza/ pneumococcus. 68\% and $59 \%$ did not get "Self care management" education and discharge plan of last hospitalization respectively. Thirty 
one percent populations had no routine OPD follow up visit within last six months of index hospitalization (Table.3). Almost all (98\%) had co-morbidities which significantly influenced the disease outcome. The mean value of BMI $( \pm \mathrm{SD})$ of the study subject was $23.72 \pm 4.63$ and $33.2 \%$ were obese, $15 \%$ were overweight, $13 \%$ were underweight.

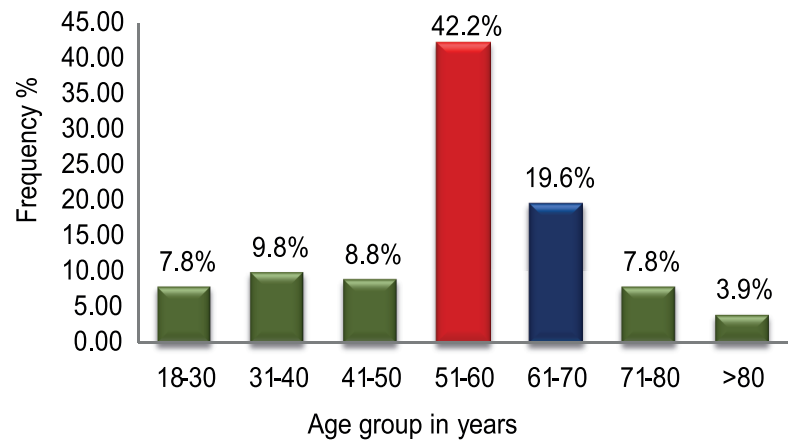

Fig.-1: Bar Diagram showing age distribution of study population $(n=102)$

$\%=$ Percentage of frequency in each group

$\mathrm{n}=$ Number of subjects

\section{Table-II}

Socio-environmental parameters of the study population $(n=102)$

\begin{tabular}{llcc}
\hline $\begin{array}{l}\text { Socio- } \\
\text { environmental } \\
\text { parameters }\end{array}$ & Distribution & $\begin{array}{c}\text { Frequency } \\
(\mathrm{N}=102)\end{array}$ & $\begin{array}{c}\text { Percentage } \\
(\%)\end{array}$ \\
\hline $\begin{array}{l}\text { Income level of } \\
\text { family }\end{array}$ & Lower class & 39 & 38.2 \\
& <11500TK/Month & & \\
& Middle class 11500- & 63 & 61.8 \\
& 200000TK/Month & & \\
& Upper class $>$ & 00 & 00 \\
& 200000TK/Month & & \\
Smoking status & Never & 38 & 37.3 \\
& Current & 29 & 28.4 \\
& Former & 35 & 34.3 \\
Alcohol status & Never & 91 & 89.2 \\
& Current & 2 & 2.0 \\
& & & \\
& Former & 9 & 8.8 \\
Other addictions & No & 80 & 78.4 \\
& yes & 22 & 21.6 \\
Living alone & No & 98 & 96.1 \\
& Yes & 4 & 3.9 \\
Family caregiver & No & 11 & 10.8 \\
& Yes & 64 & 62.7 \\
& Partial & 27 & 26.5 \\
Family help during & No & 7 & 6.9 \\
hospitalization & Yes & 68 & 66.7 \\
& Partial & 27 & 26.5 \\
\hline
\end{tabular}

$\%=$ Percentage of frequency in each group $\mathrm{n}=$ Number of subjects
Table-III

Medical advice adherence parameters of the study population $(n=102)$

Socio-adherence Distribution Frequency Percentage parameters $(\mathrm{n}=102)$ $(\%)$

\begin{tabular}{|c|c|c|c|}
\hline \multirow[t]{3}{*}{ Adherence to diet } & No & 15 & 14.7 \\
\hline & Yes & 28 & 27.5 \\
\hline & Partial & 59 & 57.8 \\
\hline Adherence to & No & 57 & 55.9 \\
\hline \multirow{2}{*}{ lifestyle } & Yes & 12 & 11.8 \\
\hline & Partial & 33 & 32.4 \\
\hline Immunization & No & 93 & 91.2 \\
\hline \multicolumn{4}{|l|}{ pneumococcus } \\
\hline Education on & No & 69 & 67.6 \\
\hline "Self care & Yes & 3 & 2.9 \\
\hline management" & Partial & 30 & 29.4 \\
\hline Discharge plan & No & 59 & 57.8 \\
\hline \multirow[t]{2}{*}{ delivered } & Yes & 16 & 15.7 \\
\hline & Partial & 27 & 26.5 \\
\hline Outpatient F/U in & No & 32 & 31.4 \\
\hline last 6 months & Yes & 70 & 68.6 \\
\hline \multicolumn{4}{|c|}{$\begin{array}{l}\%=\text { Percentage of frequency in each group } \\
n=\text { Number of subjects }\end{array}$} \\
\hline
\end{tabular}

Fig.-2: Pie chart showing the adherence to drug of the study population $(n=102)$

$\%=$ Percentage of frequency in each group $\mathrm{n}=$ Number of subjects

\section{Discussion:}

Patients with chronic congestive heart failure (CHF) required frequent rehospitalization because of the exacerbation of CHF. Previous studies examined risk factors for readmission to identify patients at high risk. 
They found associations between advanced age, prior hospital admission, the severity of illness, and medical comorbidities with hospital readmission. The conducted study was robust considering other than medical factors including the characteristics of individual, demographic and socio-environmental factors on the hospital readmission of these patients.

Precipitating acute heart failure in the form of de novo or chronic congestive heart failure was more common in 51-60 years age group with the mean age ( $\mathrm{SD} \pm$ ) of the population was $55 \pm 7$ years. ${ }^{7}$ In our study population $72 \%$ are in 51-70 years age group which is significant (p value $<0.0004$ ) when compared with the total number of admission as other study supporting these findings. Ourfinding is also different from other research survey which showed that older population suffered more from AHF.Several surveys on hospitalized AHFobserved that, the mean age $( \pm \mathrm{SD})$ of population was $69 \pm 12$ years, ${ }^{8}$ $80 \pm 10$ years $^{9}$ and $75.4 \pm 9.9$ years $^{10}$ indicating the tendency were more in older age group.Several studies foundin their study that the male participants weredominant which are almost similar to our findings. ${ }^{7,8,11}$ According to the International Congestive Heart Failure (INTER-CHF) study, 46\% hospitalized populations came from rural area, whereas $55 \%$ came from rural area (village and upazilla) area in our study. ${ }^{12}$ Probably patients came to University Cardiac Center, BSMMU to get latest medical care which was not available in countryside.

Almost all of them 100 (98\%) were married. Dokainish and Noori found $24 \%$ and $58 \%$ were single among readmission group, which are dissimilar with our study. ${ }^{12,13}$ Readmission rate was more common $51 \%$ in population who had primary level education or no education at all.Tsuchihashi et al. showed that readmission within 12 months were high among illiterate or primary education level which is higher than our findings. ${ }^{11}$

Readmission rate in patients, who have low educational level, being higher, can be a result of their poor knowledge. ${ }^{14}$ In this regard, aSwedish found that many patients have limited and little understanding and knowledge of their disease; despite that they claim the amount of information that they receive is sufficient. ${ }^{15}$ Congestive heart failure patients need sufficient and upto-date information in this area during their treatment and they need correct and proper use of several drugs. Raising patients' awareness seems essential by providing necessary continuous education proportionate to their level of literacy.
Bathaei et al. had found that $35 \%$ populations were retired but our finding is higher (51\%) due to either physicaly unfit for severity of heart failure or an event occurred among the retired group. ${ }^{16}$ Most of the patients $(62 \%)$ belonged to middle income group (11500$200000 \mathrm{Tk})$ family. Rest(38\%) belonged to lower income group $(<11500 \mathrm{Tk})$ and none of them from upper income group ( $>200000 \mathrm{Tk})$. Philbin et al. found that patients with lower income had frequent hospitalization. Generally, the income is introduced as a predictor factor of readmission in these patients ${ }^{17}$ which is consistent with the results of this study. A review of previous studies on this topic shows that the congestive heart failure is one of the costly diseases for patients' families and health care system among chronic diseases. Considering the issue, lowincome patients do not have financial power for timely follow-up of their treatment and they are compulsorily hospitalized, as the disease gets more serious. To prevent the phenomenon one should think of establishing patients' follow-up system and supporting them. ${ }^{18}$ Among thepopulation, $62 \%$ population were current smoker and former smoker and $37.3 \%$ never smoked. Noori et al.found 55\% were current smoker among readmission populationwhich was similar to our study. ${ }^{14}$

Most of thepopulation (89\%) never drank alcohol and 78\% had no other addiction. Only $4 \%$ of the population were living alone as per family bond and social culture in Bangladesh. Most of the population(62\%) had family caregiver, $27 \%$ receivedpartial care but rest $11 \%$ had no family caregiver. Tsuchihashi et al. showed that most of the patient $(80 \%)$ had caregiver service ${ }^{11}$ which is similar with our study and $21 \%$ patient lived alone and also in another study, $21 \%$ population lived alone which is dissimilar with our study. ${ }^{14}$ Above picture are in favor of sufficient nursing for the heart failure patient to reduce rehospitalization. So, adequate attention could be drawn to improve their particular patient care efficiency through interactive training or frequent group discussion. Among the populations, $38 \%$ were de-motivated forfull or partiallydrug discontinuation. In our social background, partial or total non adherence to drug was significantly influenced ( $p$ value $<0.0008$ ) by negative comments from family member or others when compared with the total number of admission. During acute hospitalization, 93\% got full or partial help from family members or from others that is similar (91\%) to the one of the study finding. ${ }^{14}$

In our study, $72 \%$ had partial or no adherence to diet. Most of the population (76\%) had partial or nonadherence to drugs and rest $25 \%$ had full adherence to 
drugs.In Japan, one of study showed that $48 \%$ hospital readmission was lack of compliance with medical and dietary treatment. ${ }^{19}$ Noori et al. had showed in their study that $69 \%$ patient had poor adherence to drug that is similar to our study result. ${ }^{13}$ This is statistically significant ( $p$ $<0.004$ ) when compared with total number of readmission for heart failure. Seventy percent patients were poor adherent to diet that is also similar to our study result. Euro-Heart Failure Survey II, identified besides arrhythmia (32.5\%), noncompliance of the drugs (31.8\%) as the most common precipitating factors of Acute Decompensate Congestive Heart Failure (ADCHF) where as higher rate of non adherence of drug (76\%) was found in our study is the main factor ${ }^{20}$.Among the respondents, $56 \%$ population had no adherence to healthy lifestyle, $12 \%$ had full adherence and rest of $32 \%$ population had partial adherence to healthy lifestyle.

Most of the population, (91\%) were not immunized against influenza / pneumococcus during the course of heart failure which is highly recommended from various guidelines. As HF is inevitable consequence of some cardiac and non cardiac disease process and emerging non communicable chronic diseases in Bangladesh and similar other developing countries, "Self care management" strategies should be firmly applied like self care management in diabetes mellitus. ${ }^{21}$ Majority of population (68\%)did not get "Self care management" education in our study. Significant percentage of (59\%)population did not get discharged plan in the last hospitalization but in the discharge phase of acute heart failure management, proper discharge instructions to patients and their attendants are strongly recommended. ${ }^{22}$ It is disappointing that only $3 \%$ and $16 \%$ got "Self care management" education and discharged instructionsduring the last hospitalization respectively. Patients follow-up plans must be in place prior to discharge and clearly communicated to the primary care team; patient should be (i) reviewed by their general practitioner within 1 week of discharge; (ii) should be seen by the hospital cardiology team within 2 weeks of discharge if feasible. ${ }^{23}$ But in our study $69 \%$ patientshad at least single out patient based routine followup within last 6 months. On the contrary, one of the studies done abroad showed that at the time of discharge, $65 \%$ of patients or families had received education on discharge planning. ${ }^{11}$

Among 102 patients, 38\% had history of single hospitalization within last year of index hospitalization, $18 \%$ had four or more hospitalization within last year of index hospitalization, and $19 \%$ and $16 \%$ had two and three hospitalization within last year of index hospitalization respectively. Hasan et al. showed in the hospital readmission prediction model study that $38 \%$ population had no admission history, $25 \%$ had single time, $13 \%$ had twice, $7 \%$ had thrice, and $17 \%$ had four or more admission in last year from index hospitalization ${ }^{14}$.

\section{Conclusion:}

Patients hospitalized with congestive heart failure have a high risk for readmission after discharge. The result of the this study showed that major socio-environmental factors increase the risk of readmission due to congestive heart failure alongside with medical and demographic factors. This study suggests that applying some plans in vulnerable groups and conducting some education interventions to optimize the patient's awareness of drug, diet, life style and some medical advice adherence would be useful in further decreasing readmission due to congestive heart failure.

\section{References}

1. Zipes D, Libby P, Bonow R, Braunwald E. A textbook of cardiovascular medicine. pp858. Phila WB Saunders. 2005;

2. Ho KK, Pinsky JL, Kannel WB, Levy D. The epidemiology of heart failure: the Framingham Study. J Am Coll Cardiol. 1993;22(4): A6-13.

3. Cowie M, Fox K, Wood D, Metcalfe C, Thompson S, Coats A, et al. Hospitalization of patients with heart failure. A population-based study. Eur Heart J. 2002;23(11):877-85.

4. Krumholz HM, Parent EM, Tu N, Vaccarino V, Wang Y, Radford MJ, et al. Readmission after hospitalization for congestive heart failure among Medicare beneficiaries. Arch Intern Med. 1997;157(1): 99-104.

5. Adler NE, Newman K. Socioeconomic disparities in health: pathways and policies. Health Aff (Millwood). 2002;21(2): 60-76.

6. Ghali JK, Kadakia S, Cooper R, Ferlinz J. Precipitating factors leading to decompensation of heart failure: traits among urban blacks. Arch Intern Med. 1988;148(9):2013-6.

7. Fatima M, Niaz N. Factors Precipitating Acute Heart Failure. Ann Pak Inst Med Sci. 2014;10(1):33-8.

8. Nieminen MS, Brutsaert D, Dickstein K, Drexler H, Follath F, Harjola V-P, et al. EuroHeart Failure Survey II (EHFS II): a survey on hospitalized acute heart failure patients: description of population. Eur Heart J. 2006;27(22):2725-36.

9. Hauptman PJ, Goodlin SJ, Lopatin M, Costanzo MR, Fonarow GC, Yancy CW. Characteristics of patients hospitalized with acute decompensated heart failure who are referred for hospice care. Arch Intern Med. 2007;167(18):1990-7.

10. Michalsen A, König G, Thimme W. Preventable causative factors leading to hospital admission with decompensated heart failure. Heart. 1998;80(5):437-41.

11. Tsuchihashi M, Tsutsui H, Kodama K, Kasagi F, Setoguchi S, Mohr $\mathrm{M}$, et al. Medical and socioenvironmental predictors of hospital readmission in patients with congestive heart failure. Am Heart J. 2001;142(4):20A-26A. 
12. Dokainish H, Teo K, Zhu J, Roy A, Al-Habib K, ElSayed A, et al. Heart failure in low-and middle-income countries: Background, rationale, and design of the INTERnational Congestive Heart Failure Study (INTER-CHF). Am Heart J. 2015;170(4):627-34.

13. Noori A, Shokoohi M, Baneshi MR, Naderi N, Bakhshandeh H, Haghdoost AA. Impact of socio-economic status on the hospital readmission of Congestive Heart Failure patients: a prospective cohort study. Int J Health Policy Manag. 2014;3(5):251.

14. Hasan O, Meltzer DO, Shaykevich SA, Bell CM, Kaboli PJ, Auerbach $\mathrm{AD}$, et al. Hospital readmission in general medicine patients: a prediction model. J Gen Intern Med. 2010;25(3):211-9.

15. Ågård A, Hermerén G, Herlitz J. When is a patient with heart failure adequately informed? A study of patients' knowledge of and attitudes toward medical information. Heart Lung J Acute Crit Care. 2004;33(4):219-26.

16. Bathaei S, Ashktorab T, Zohari Anbuhi S, Alavi Majd H, Ezati J. Personal factors contributing to readmission of patients with congestive heart failure. J Crit Care Nurs. 2009;2(3):109-12.

17. Philbin EF, Dec GW, Jenkins PL, DiSalvo TG. Socioeconomic status as an independent risk factor for hospital readmission for heart failure. Am J Cardiol. 2001;87(12):1367-71.

18. Pitt B, Gwadry-sridhar F, Flintoft V, Lee D. a peridischarge multidisciplinary treatment programme reduces readmissions in heart failure. Evid Based Med. 2005;10(4):108.
19. Tsuchihashi M, Tsutsui H, Kodama K, Kasagi F, Takeshita A. Clinical characteristics and prognosis of hospitalized patients with congestive heart failure. Jpn Circ J. 2001;64(12):953-9.

20. Nieminen, MS, Brutsaert, D, Dickstein, K, Drexler, H, Follath, F, Harjola, VP, Hochadel, M, Komajda, M, Lassus, J, Lopez-Sendon, JL, and Ponikowski, P 2006. "EuroHeart Failure Survey II (EHFS II): a survey on hospitalized acute heart failure patients: description of population". European heart journal, vol. 27(22), pp.2725-2736.

21. Smith CE, Piamjariyakul U, Wick JA, Spertus JA, Russell C, Dalton KM, et al. Multidisciplinary Group Clinic Appointments: The SelfManagement and Care of Heart Failure (SMAC-HF) Trial: Smith et al: Reducing HF Rehospitalizations SMAC-HF. Circ Heart Fail. 2014 Nov;7(6):888-94.

22. Harinstein ME, Flaherty JD, Fonarow GC, Mehra MR, Lang RM, Kim RJ, et al. Clinical assessment of acute heart failure syndromes: emergency department through the early post-discharge period. Heart. 2011;97(19):1607-18.

23. Ponikowski P, Voors AA, Anker SD, Bueno H, Cleland JG, Coats AJ, et al. 2016 ESC Guidelines for the diagnosis and treatment of acute and chronic heart failure: The Task Force for the diagnosis and treatment of acute and chronic heart failure of the European Society of Cardiology (ESC) Developed with the special contribution of the Heart Failure Association (HFA) of the ESC. Eur Heart J. 2016;37(27):2129-200. 